\title{
The curious case of QWERTY
}

\begin{tabular}{|c|c|c|c|c|c|c|c|c|c|c|c|c|c|c|}
\hline & 1 & 2 & 3 & 4 & & 5 & 6 & 7 & 7 & 8 & 9 & 0 & - & $=\left[\begin{array}{l}\text { Back } \\
\text { Space }\end{array}\right.$ \\
\hline Tab & $\mathbf{Q}$ & $w$ & $E$ & & $\mathbf{R}$ & $T$ & & $Y$ & $\mathbf{u}$ & 1 & 0 & $\mathbf{P}$ & $1 / 2$ & \\
\hline Loc & A & & 5 & D & $F$ & & $\mathbf{G}$ & $\bar{H}$ & J & $\bar{K}$ & $\mathrm{~K}$ & $\mathrm{~L}:$ & $; \%$ & Return \\
\hline Shi & & $z$ & $\bar{x}$ & & c & $\mathbf{v}$ & $E$ & 3 & $\mathbf{N}$ & $\mathbf{M}$ & ' & . & $?$ & Shift \\
\hline TRA & DוT & DNAL & & & & & & pac & $\mathrm{eBa}$ & & & & & \\
\hline
\end{tabular}

\begin{tabular}{|c|c|c|c|c|c|c|c|c|c|c|c|c|c|}
\hline 1 & $\underline{2}$ & & 3 & 4 & 5 & 6 & 5 & 7 & 8 & 9 & - & & $=\begin{array}{l}\text { Back } \\
\text { Space }\end{array}$ \\
\hline Tab & $"$ & ' & 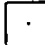 & & ? & $\mathbf{Y}$ & $\mathbf{F}$ & $\mathbf{G}$ & C & $\mathbf{R}$ & $\mathbf{L}$ & $?$ & \\
\hline Contro: & $\mathbf{A}$ & 0 & 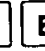 & $E$ & $\mathbf{u}$ & 1 & D & H & I & 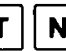 & I & $\mathbf{s}$ & Return \\
\hline Shift & & & $\mathbf{Q}$ & $J$ & 1 & & $x$ & B & $\mathbf{M}$ & $w$ & v & $z$ & Shift \\
\hline & & & & & & & Spac & ce Bar & & & & & Lock \\
\hline
\end{tabular}

The standard typewriter keyboard layout, known almost affectionately as QWERTY, was laid out in the 1870 s by Christopher L Sholes. He decided upon this particular spread of letters as a means of slowing typists down, not speeding up their work. The first Remington machines had fairly straightforward keyboards, but the typists handled them so well that the keys jammed - and so Sholes was compelled to design the QWERTY layout in the interests of machines that wouldn't jam.

The result, a hundred years later, is a keyboard that is universally used but also too slow and cumbersome for the electronic age. In fact, machines were fast enough mechanically in the 1930 s for a more efficient layout, but by that time inertia had set in, people were used to QWERTY, enormous numbers of machines were being produced, typing schools were geared to this particular arrangement, and nobody wanted to change. But, as the International Herald Tribune put it (19 Mar 85):

'Then came August Dvorak, a University of Washington psychologist who was a pioneer of ergonomics, the study of the interaction between man and machine. Mr. Dvorak designed a keyboard built for speed, putting all five vowels and the five most common consonants on the center, or home, row, right under the fingers.' Dvorak had studied the frequency patterns of English letters in combination, and come up with his Dvorak Simplified Keyboard or DSK, but, as Hugh Pearman noted in The Observer (25 Aug 85), 'the world failed to beat a path to Dvorak's door'.

The reason the press is reporting the matter now however, is simple: times have changed and we need Dvorak. Sadly, however, he died in 1975, just before the electronic dawn broke for typewriters.

There are evidently some 30 million QWERTY machines in existence, and one-tenth as many Dvoraks. That is already a significant shift, and further shifts can be anticipated. Pearman notes: 'Many manufacturers are prepared for the DSK explosion, according to Virginia Russell, head of the Dvorak Federation ... They are just awaiting the right 'marketing moment.'

\section{Non-stick accents}

Recently The Times of London noted that 'regional accents [in Britain] are more acceptable these days, and rightly so' (13 Dec 85). The acceptability refers to southern English educational and governing circles, as is made clear by the follow-up: 'But as any Southerner who has struggled with Auf Wiedersehen Pet or a report in the Ulster tones of BBC TV's John Cole will know, there can be pitfalls.'

The double-edged compliment to the more confident regional forms, however, was a lead-in to a brief report on some language research undertaken at the Department of Psychology of the University of Lancaster, well to the north in England. This survey 'has shown that listeners to news reports presented in an accent with which they are not familiar retain a lot less information than when the report is presented in good old nondescript "received pronunciation"., Evidently, when given a comprehension test immediately after hearing three news stories, volunteer students scored 20 per cent less on Geordie (from Newcastle upon Tyne) than on RP, and did even worse on accents from Yorkshire, the West Midlands of England and from Northern Ireland. Re-call, it is claimed, was also adversely affected.

The researchers involved - Wendy Bottriell and F N Johnson - offered the explanation that the listener might have taken RP as the more prestigious form 'and processes the information accordingly' or 'the RP message may simply be less ambiguous, the listener could be distracted by the regional accent or have to concentrate more on individual words rather than the overall message.' The reporter noted that the studies 'were conducted on young adults who tend to be tolerant of regional accents,' and the report appeared in The Times's section entitled 'Medical Briefing'.

\section{Latter-day Latin}

In the News section of ETl (Jan 85), we reported on publishing efforts in Europe to revive and disseminate Latin, including renderings of such non-Classical classics as Donald Duck, Mickey Mouse and Snoopy - or Donaldus Anas, Michael Musculus and Snupius as they became. We also quoted the Italian publisher, Rev. Lamberto Pigini, as saying that 'the language of the future in Europe must necessarily be Latin. English won't do, because the French would never accept it $\ldots$ and the European languages would become disappearing dialects.'

It now seems that powerful factors in the Vatican itself - the last practical stronghold of the Latin language - may have begun to tip the scales - but against Pigini's vision. According to Leslie
Childe in the Sunday Telegraph (1 Dec 85), even Pope John Paul has been heard to say: 'I am talking in English because it is the modern Latin.'

At the recent World Synod of Bishops convened in the Vatican, many of the dignitaries of the Roman Catholic Church addressed the assembly not in Latin but in English, while others used Spanish, French or German. 'The situation has become critical,' observed Father Carlo Egger, the Vatican's foremost Latinist. He added that Americans were the least likely to use Latin well, followed by the Africans. 'The Asians are rather better.' It would also appear that the daily handouts at the Synod were prepared in English, then translated into other languages. The Pope may well be right.

Seen in Heathrow Terminal I London,
the following sign:
This door is alarmed and must only
be used in an emergency.
Seen in a department store in Milan,
Italy, the following sign:
Al piano inferiore -
giocchi elettronici
video games
puzzles
war games
posters
articoli regalo
gadgets

